\title{
ESPÉCIES EXÓTICAS NA ARBORIZAÇÃO DE VIAS PÚBLICAS NO MUNICÍPIO DE FAROL, PR, BRASIL
}

\author{
Mariana Irene Hoppen ${ }^{1}$, Helizabett Fernanda Divensi² ${ }^{2}$ Rodolfo Faquini Ribeiro ${ }^{3}$, \\ Marcelo Galeazzi Caxambú ${ }^{4}$
}

\section{RESUMO}

A introdução de espécies exóticas no meio urbano se dá muitas vezes pelo mau planejamento da arborização urbana e muitas vezes pelo desconhecimento da legislação. Um dos maiores problemas das espécies exóticas na arborização urbana é que as mesmas podem sair de controle, competindo e ameaçando as espécies nativas. O município de Farol - PR possui menos de 4.000 habitantes, localizado no Noroeste do Paraná, sendo que a arborização urbana não foi planejada. $O$ objetivo deste trabalho foi analisar quantitativamente as espécies exóticas invasoras presentes na arborização urbana do mesmo. A metodologia utilizada foi a de caminhada e observação, durante três visitas ao Município de Farol/PR, durante o mês de Maio de 2012. Foram encontradas 33 espécies, perfazendo 798 indivíduos compondo a arborização do município. Destas, 10 espécies são consideradas exóticas invasoras, representando $18 \%$ da composição florística existente dentre as espécies exóticas invasoras, Ligustrum lucidum W. T. Aiton (alfeneiro) com 106 indivíduos foi a de maior ocorrência. Dentre as espécies, foi registrada a ocorrência de Murraya paniculata (L.) Jacq, que embora não seja exótica invasora, tem proibida sua comercialização, plantio, produção de sementes e transporte do estado do Paraná. Para a adequação da arborização urbana é necessário um planejamento que contemple, preferencialmente, espécies nativas que se adaptem às características locais, proporcionando benefícios ecológicos, estéticos, econômicos e sociais.

Palavras-chave: Invasão biológica; Vias públicas; Arborização urbana.

Recebido em 02.11.2012 e aceito em 22.04.2014

1 Engenheira Ambiental, Mestranda em Ciência e Tecnologia Ambiental na UTFPR. Campo Mourão/PR. Email: mahoppen@hotmail.com

2 Estudante de graduação em Engenharia Ambiental da UTFPR, Campo Mourão/PR. Email: ferdivensi@hotmail.com

3 Estudante de graduação em Engenharia Ambiental da UTFPR, Campo Mourão/PR. Email:rofakini@hotmail.com

4 Engenheiro Florestal, Professor da Universidade Tecnológica Federal do Paraná, Campus Campo Mourão/PR. Email: mgcaxambu@yahoo.com.br 


\section{INVASIVE ALIEN SPECIES AS URBAN TREES IN THE STREETS OF FAROL, PR, BRAZIL}

\section{ABSTRACT}

The introduction of exotic species in urban areas occurs often by poor planning of urban forestry and often by ignorance of legislation. One of the biggest problems of exotic species in urban trees is that they can get out of control, competing and threatening native species. The city of Farol - PR has less than 4,000 inhabitants, located in the Northwest of Paraná, and urban forestry was not planned. The objective of this study was to analyze quantitatively the invasive species present in the same urban forestry. The methodology used was to walk and observation of three visits to the City of Farol / PR, during the month of May 2012. We found 33 species, totaling 798 individuals composing the afforestation of the municipality. Of these, 10 species are considered invasive, representing $18 \%$ of the floristic composition among existing invasive exotic species, Ligustrum lucidum W. T. Aiton (privet) with 106 individuals was the most frequent. Among the species was recorded the occurrence of Murraya paniculata (L.) Jacq, which although not exotic invasive, has banned their sale, planting, seed production and transportation of the state of Paraná. For the suitability of urban forestry planning is necessary to contemplate, preferably native species that are adapted to local conditions, providing ecological benefits, aesthetic, economic and social.

Keywords: Biological invasion; Thoroughfares; Urban forestry

\section{INTRODUÇÃO}

A arborização de ruas, além de ser um serviço público, é um patrimônio que deve ser conhecido e preservado para as futuras gerações. Sua existência deve procurar atender os requisitos de conforto ambiental, o bem-estar psíquico e psicológico da população, além de proporcionar beleza aos centros urbanos (BIONDI; ALTHAUS, 2005; COPEL, 2009).

A vegetação na área urbana tem algumas funções que são classificadas por Alvarez (2004), que considera que a função de lazer deve satisfazer as necessidades físicas, psicológicas e sociais; a função ecológica possui relação com o clima e com a proteção e 
preservação da fauna e flora; e, por fim, a função estética, que tem por objetivo modelar, enfeitar e diversificar a estrutura urbana.

Para Matos e Queiroz (2009), as árvores participam de nosso cotidiano, sejam oferecendo remédios, alimentos, sombra ou bem-estar, sejam contribuindo para o controle de erosão, deslizamentos ou para o conforto térmico. Cidades bem arborizadas são lembradas por serem agradáveis e bonitas.

O histórico da preocupação com a arborização urbana no Brasil é recente, e para os gestores que a desenvolvem, a maior ênfase se dá em plantar árvores que diversifiquem a paisagem, quando o objetivo principal deveria ser implantar em suas arborizações espécies que se relacionassem com as características locais (MELO; ROMANINI, 2008). Com isso, cada vez mais, espécies exóticas invasoras vêm sendo implantadas na arborização de vias públicas, parques, bosques e praças, tendo em vista o desconhecimento das normas e da legislação existente, bem como da existência de invasoras potenciais, isto é, plantas que se tornaram invasoras em ambientes com condições ecológicas àquelas do Brasil e que não deveriam ser implantadas na arborização urbana, sob risco de se tornarem novas espécies invasoras.

Martini (2008) postula que no plano diretor de cada cidade deve constar um plano de arborização urbana, com gerenciamento, manutenção e preservação das espécies arbóreas presentes. Na intenção de propor medidas mitigadoras para a melhoria da arborização da cidade e assim oferecer melhores condições ambientais e evitar transtornos aos moradores que na maioria das vezes convivem com a escassez da vegetação arbórea ou pelo confronto das árvores com a rede elétrica, pelos danos as ruas e calçadas e por espécies arbóreas que não são propicias ao paisagismo.

Segundo Matos e Queiroz (2009) foi na época do Brasil colônia que as espécies exóticas começaram a ser introduzidas no país, trazidas da Europa para aproximar a paisagem brasileira com as terras européias. Entretanto a difusão de espécies exóticas nos dias de hoje está relacionada principalmente com o interesse por plantas ornamentais.

Espécie exótica invasora é aquela espécie exótica que, sem a intervenção direta do homem, avança sobre as populações locais e ameaça habitats naturais ou seminaturais, produzindo impactos ambientais e/ou econômicos e/ou sociais e/ou culturais (IAP, 2009; DARRIGRAN, 1997).

De acordo com o Ministério do Meio Ambiente - MMA (2012) e com o IAP (2009), as espécies exóticas invasoras são consideradas uma das maiores ameaças biológicas ao ambiente, exatamente por terem as características descritas acima, além de oferecerem riscos à saúde humana. 
Plantas exóticas podem ter algumas vantagens, como crescimento rápido e vigor, mas essas características podem caracterizar a espécie o hábito invasor. Afetando o desenvolvimento das espécies nativas, uma vez que compete com as mesmas por água, luz e nutrientes (MATOS; QUEIROZ, 2009).

A invasão de espécies exóticas invasoras pode contribuir para alterações em importantes componentes ecológicos, como o ciclo de nutrientes, estrutura da comunidade vegetal, interação entre planta-polinizador, entre outras alterações que comprometem a dinâmica do ecossistema em questão. A invasão de espécies de grande porte acelera esses processos inclusive a perda de diversidade (ZILLER, 2001).

De acordo com a mesma autora, entre as características que ampliam o potencial de invasão de uma planta estão a produção de grandes quantidades de sementes pequenas, com dispersão eficiente e grande tempo de permanência no solo, crescimento rápido, maturação precoce, reprodução também por brotação, floração e frutificação mais longas, pioneirismo, adaptação a áreas degradadas, eficiência reprodutiva e presença de princípios alelopáticos. Características essas freqüentemente encontradas associadas a espécies exóticas.

Além disso, a Portaria do IAP $\mathrm{n}^{\circ} 125$, de 07 de agosto de 2009 , considera que as espécies exóticas invasoras podem produzir formas híbridas ao cruzarem com espécies nativas, ocupando o espaço das mesmas e diminuindo assim a abundância desses indivíduos, prejudicando diretamente a diversidade e as características da formação florestal do local.

A ISA - International Society of Arboriculture, estabelece que para a preservação da diversidade de espécies, a população de uma determinada espécie não deva ultrapassar $15 \%$ do total de espécimes existentes no ambiente urbano (COPEL, 2009).

Entretanto, para Blum et al. (2008), as espécies exóticas, se implantadas de forma planejada, não oferecem risco a biodiversidade do local, entretanto, quando introduzidas de maneira desordenada e sem planejamento, algumas espécies acabam tornando-se invasoras, por terem a capacidade de dominar o ambiente e causarem risco a biodiversidade.

A eficiência da arborização urbana depende exclusivamente do seu planejamento. Planejar é escolher a espécie certa para o local certo, sem desrespeitar os limites naturais do meio (BIONDI; ALTHAUS, 2005) ou ainda, de acordo com a COPEL (2009) é utilizar a árvore certa para o lugar certo, ou seja, árvores compatíveis com os equipamentos públicos da urbe. 
O objetivo desse estudo foi quantificar as espécies exóticas presentes na arborização das vias públicas urbanas do município de Farol, Paraná, a fim de propor espécies adequadas para a substituição.

\section{MATERIAIS E MÉTODOS}

\section{Área de Estudo}

O município de Farol está localizado na região noroeste do estado do Paraná a altitude média de 630 m e com população estimada de 3.472 habitantes (IBGE, 2010).

De acordo com a classificação apresentada por Köeppen (1978) o clima da região caracteriza-se com Cfa, ou seja, subtropical úmido mesotérmico, com temperaturas entre 18 ${ }^{\circ} \mathrm{C}$ e $22^{\circ} \mathrm{C}$, com verões quentes, sem freqüência de geadas, sem estação seca definida, porem com maior concentração de chuvas no verão.

Quanto ao tipo de solo há predominância do Latossolo e em menor proporção o Arenito Caiuá, o que ocorre em função do município estar em zona de transição entre os solos provenientes da intemperização do Basalto da Formação Serra Geral e do Arenito Caiuá (EMBRAPA, 2006). Com relação ao relevo, Martins (2003) descreve que se caracteriza por: a) suavemente ondulado $=40 \%$; b) ondulado $=50 \%$ e c) $10 \%$ montanhoso.

De acordo com a classificação das Unidades Fitogeográficas do Estado do Paraná, proposta por Roderjan et al. (2002), o município de Farol está situado em uma região dominada pela Floresta Estacional Semidecidual. Esse tipo de vegetação apresenta duas estações climáticas bem definidas, sendo uma tropical com chuvas no verão e estiagem bem acentuada, e subtropical sem período seco e baixas temperaturas no inverno. Essa formação caracteriza-se principalmente pela decidualidade da vegetação nas estações de outono e inverno.

\section{Coleta e Análise dos Dados}

A coleta dos dados foi feita através de caminhadas pelas ruas do Município, em três expedições à cidade de Farol durante o mês de maio de 2012. Essas visitas duraram em média 6 horas, e as informações como a identificação da planta e número de indivíduos por espécie, foram registradas em campo. A identificação das árvores foi realizada de maneira 
direta, utilizando para isso chaves de identificação ou consulta ao Herbário da Universidade Tecnológica Federal do Paraná (HCF) quando necessário.

O sistema de classificação utilizado foi o APG III (2009). Para os epítetos específicos foi seguida a Lista da Flora do Brasil (2012) e The International Plant Name Index (2012).

Foram considerados como indivíduos pertencentes à arborização urbana apenas os que se encontravam no alinhamento regular da prefeitura de Farol.

Assim como em Blum et al. (2008) no levantamento das espécies exóticas invasoras no município de Maringá -PR e Sampaio et al. (2011) no levantamento de espécies exóticas de três bairros de Campo Mourão - PR, também foi utilizada a classificação de Zalba (2006) para a procedência das espécies:

- Exótica Extra Ecossistemas Brasileiros (ex-BR): espécie que não ocorre espontaneamente nos ecossistemas existentes em território brasileiro, sendo oriunda de ecossistemas de outros países;

- Exótica Extra Ecossistemas Paranaenses (ex-PR): espécie que não ocorre espontaneamente em ecossistemas paranaenses, sendo oriunda de ecossistemas distintos existentes em outros estados do Brasil;

- Exótica Extra Ecossistema de Floresta Estacional Semidecidual Paranaense (exFESPR): espécie que não ocorre espontaneamente dentro dos limites fitogeográficos da Floresta Estacional Semidecidual no Paraná, mas que pode ocorrer em outras tipologias vegetais do Estado ou mesmo em outros estados do Brasil;

- Nativa: espécie que ocorre espontaneamente na região de Farol, típica da Floresta Estacional Semidecidual, que caracterizavam originalmente a região.

Para a análise dos dados referentes ao status invasor da espécie (origem) foram utilizadas a Portaria $\mathrm{n}^{0125}$, de 07 de agosto de 2009 do IAP, que reconhece as espécies exóticas invasoras no estado do Paraná e estabelece normas para seu controle e a base de dados do Instituto Hórus de Desenvolvimento e Conservação Ambiental (2012).

\section{RESULTADOS E DISCUSSÃO}

Foram amostradas 798 árvores na arborização urbana de Farol - PR, que se distribuíram em 33 espécies, pertencentes a 18 famílias (Tabela 1). Destas espécies, 10 são classificadas como exóticas invasoras, representando $18 \%$ da composição florística da arborização urbana do município de Farol - PR. 
Tabela 1. Espécies encontradas na Arborização Urbana de Farol - PR

Table 1. Species found in Urban Forestation of Farol - PR

\begin{tabular}{|c|c|c|c|c|}
\hline Família/Espécie & $\begin{array}{l}\text { Nome } \\
\text { Vulgar }\end{array}$ & NI & Origem & Procedência \\
\hline \multicolumn{5}{|l|}{ ANACARDIACEAE } \\
\hline Schinus molle L. & Chorão & 143 & Nativa & ex-PR \\
\hline Mangifera indica L. & Mangueira & 12 & $\begin{array}{l}\text { Exótica/l } \\
\text { nvasora }\end{array}$ & ex-BR \\
\hline \multicolumn{5}{|l|}{ ARECACEAE } \\
\hline Phoenix roebelenii O'Brien & $\begin{array}{l}\text { Tamareira } \\
\text { anã }\end{array}$ & 44 & Exótica & ex-BR \\
\hline \multicolumn{5}{|l|}{ BIGNONIACEAE } \\
\hline Handroanthus heptaphyllus (Vell.) Mattos & Ipê-roxo & 1 & Nativa & Nativa \\
\hline Handroanthus chrysotrichus (Mart. ex DC.) Mattos & Ipê Amarelo & 6 & Nativa & ex-FESPR \\
\hline \multicolumn{5}{|l|}{ CHRYSOBALANACEAE } \\
\hline Licania tomentosa (Benth.) Fritsch & Oiti & 41 & Nativa & ex-PR \\
\hline \multicolumn{5}{|l|}{ COMBRETACEAE } \\
\hline Terminalia catappa L. & $\begin{array}{l}\text { Chapéu de } \\
\text { sol }\end{array}$ & 1 & $\begin{array}{l}\text { Exótica/l } \\
\text { nvasora }\end{array}$ & ex-BR \\
\hline \multicolumn{5}{|l|}{ CUPRESSACEAE } \\
\hline Juniperus chinensis L. & $\begin{array}{l}\text { Zimbro- } \\
\text { chinês }\end{array}$ & 1 & Exótica & ex-BR \\
\hline \multicolumn{5}{|l|}{ FABACEAE } \\
\hline Bauhinia variegata $L$. & Pata de Vaca & 11 & Exótica & ex-BR \\
\hline Cajanus cajan (L.) Huth & $\begin{array}{l}\text { Feijão } \\
\text { Guandú }\end{array}$ & 4 & Exótica & ex-BR \\
\hline Delonix regia (Bojer ex Hook.) Raf. & Flamboyant & 18 & Exótica & ex-BR \\
\hline Holocalyx balansae Micheli & Alecrim & 1 & Nativa & Nativa \\
\hline $\begin{array}{l}\text { Leucaena leucocephala } \\
\text { (Lam.) R. de Wid. }\end{array}$ & Leucena & 1 & $\begin{array}{l}\text { Exótica/l } \\
\text { nvasora }\end{array}$ & ex-BR \\
\hline $\begin{array}{l}\text { Poincianella pluviosa var. peltophoroides (Benth.) } \\
\text { L.P.Queiroz }\end{array}$ & Sibipiruna & 270 & Nativa & ex-PR \\
\hline $\begin{array}{l}\text { Racosperma podalyriifolium (A. Cunn. ex.G. Don) } \\
\text { Pedley }\end{array}$ & $\begin{array}{l}\text { Acácia } \\
\text { Mimosa }\end{array}$ & 4 & Exótica & ex-BR \\
\hline Tipuana tipu (Benth.) Kuntze & Tipuana & 3 & Exótica & ex-BR \\
\hline \multicolumn{5}{|l|}{ LAURACEAE } \\
\hline Cinnamomum verum J.Presl. & Canela & 2 & Exótica & ex-BR \\
\hline Persea americana L. & Abacateiro & 1 & Exótica & ex-BR \\
\hline \multicolumn{5}{|l|}{ LYTHRACEAE } \\
\hline Legerstroemia indica L. & Extremosa & 1 & Exótica & ex-BR \\
\hline Punica granatum L. & Romã & 1 & Exótica & ex-BR \\
\hline \multicolumn{5}{|l|}{ MALVACEAE } \\
\hline Hibiscus rosa-sinensis $\mathrm{L}$. & Hibisco & 3 & Exótica & ex-BR \\
\hline
\end{tabular}




\begin{tabular}{|c|c|c|c|c|}
\hline \multicolumn{5}{|l|}{ MELASTOMATACEAE } \\
\hline Tibouchina granulosa (Desr.) Cogn. & Quaresmeira & 62 & Nativa & ex-PR \\
\hline Tibouchina sellowiana Cogn. & Quaresmeira & 2 & Nativa & ex-FES PR \\
\hline \multicolumn{5}{|l|}{ MELIACEAE } \\
\hline Cedrela fissilis Vell. & Cedro & 1 & Nativa & Nativa \\
\hline Melia azedarach L. & Cinamomo & 1 & $\begin{array}{l}\text { Exótica/l } \\
\text { nvasora }\end{array}$ & ex-BR \\
\hline \multicolumn{5}{|l|}{ MYRTACEAE } \\
\hline Psidium guajava L. & Goiaba & 8 & $\begin{array}{l}\text { Exótica/l } \\
\text { nvasora }\end{array}$ & ex-BR \\
\hline \multicolumn{5}{|l|}{ MORACEAE } \\
\hline Ficus benjamina L. & Ficus & 17 & Exótica & ex-BR \\
\hline \multicolumn{5}{|l|}{ OLEACEAE } \\
\hline Ligustrum lucidum W. T. Aiton & Alfeneiro & 106 & $\begin{array}{l}\text { Exótica/l } \\
\text { nvasora }\end{array}$ & ex-BR \\
\hline \multicolumn{5}{|l|}{ PROTEACEAE } \\
\hline Grevillea banksii R. Br. & $\begin{array}{l}\text { Grevílea de } \\
\text { jardim }\end{array}$ & 2 & $\begin{array}{l}\text { Exótica/l } \\
\text { nvasora }\end{array}$ & ex-BR \\
\hline Grevillea robusta A. Cunn. ex R. Br. & Grevílea & 4 & $\begin{array}{l}\text { Exótica/l } \\
\text { nvasora }\end{array}$ & ex-BR \\
\hline \multicolumn{5}{|l|}{ ROSACEAE } \\
\hline $\begin{array}{l}\text { Eriobotrya japonica } \\
\text { (Thunb.)Lindl. }\end{array}$ & Nêspera & 3 & $\begin{array}{l}\text { Exótica/l } \\
\text { nvasora }\end{array}$ & ex-BR \\
\hline \multicolumn{5}{|l|}{ RUTACEAE } \\
\hline Murraya paniculata (L.) Jacq & Murta & 16 & Exótica & ex-BR \\
\hline Citrus limon (L.) Burm. f. & Limoeiro & 6 & $\begin{array}{l}\text { Exótica/l } \\
\text { nvasora }\end{array}$ & ex-BR \\
\hline
\end{tabular}

Como podemos observar na Figura 1, o número de espécies exóticas supera o de espécies nativas, entretanto a quantidade de indivíduos de espécies nativas é maior na composição da arborização urbana do município. Já, as espécies exóticas invasoras, compõem 18\% de toda a composição da arborização urbana, distribuídas em 10 espécies.

Dentre as espécies exóticas encontradas, as que tiveram maior ocorrência foram: Ligustrum lucidum com 106 indivíduos, Phoenix roebelenii com 44 indivíduos e Delonix regia com 18 indivíduos, representando mais de $20 \%$ da composição arbórea urbana do município, sendo destas, apenas Ligustrum lucidum considerada exótica invasora.

Das três espécies mais abundantes, Delonix regia, segundo Beckes e Irgang (2005) tem origem africana e crescimento rápido e não suporta frio e geada, possuindo um enraizamento superficial, danificando ruas e calçadas e ainda interferindo na fiação elétrica, sendo orientada sua retirada. No entanto, para Blum et al. (2008), essa espécie não tem capacidade de reprodução e dispersão na região, não oferecendo riscos a biodiversidade. 
Ligustrum lucidum é árvore nativa da China e Coréia que foi introduzida por fins ornamentais e para compor a arborização urbana. Possui grande quantidade de frutos que tem grande tempo de frutificação, competindo com as espécies nativas e é muito comum na arborização urbana, apesar de não ter relevância paisagística, danificar ruas e calçadas e ainda manter contato com a fiação elétrica. Além disso, os frutos são tóxicos para pessoas e a ingestão causa sintomas como náusea, dores de cabeça, dores abdominais, vômitos, diarréia, pressão baixa e hipotermia (INSTITUTO HÓRUS, 2012).

É importante salientar a presença da Murraya paniculata, espécie exótica que foi grandemente utilizada na arborização urbana por apresentar porte pequeno, não atingir a rede elétrica e nem danificar as calçadas e ruas, mas que foi banida do Paraná, através da

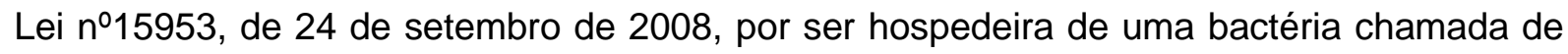
Candi-datus liberibacter spp. disseminada pelo inseto vetor Diaphorina citri, transmissor da praga denominada Huanglongbing (HLB - Greening).

Contudo, algumas espécies, mesmo sendo consideradas exóticas, não são capazes de realizar invasão biológica e por isso não apresentam riscos à diversidade nativa, dentre elas podemos citar: Lagerstroemia indica, Hibiscus rosa-sinensis e Delonix regia (BLUM et al. 2008), embora sabe-se os danos que o flamboyant causa a estrutura urbana. Já a extremosa e o hibisco são espécies de grande aceitação na arborização urbana por embelezarem as ruas e avenidas sem causar maiores danos.

Espécies que também apresentam problemas relevantes em relação aos danos a ruas e calçadas são: Tipuana tipu, Melia azedarach e Ficus benjamina.

Embora, algumas espécies exóticas não tenham caráter invasor, deve-se ter cuidado elevado com essas espécies, pois o potencial invasor nas espécies exóticas é muito maior, em relação às espécies nativas.

Com relação à procedência das espécies, apenas $9 \%$ são nativas e $73 \%$ são classificadas com exóticas no Brasil (Figura 1), ou seja, que não ocorrem espontaneamente no país. 
Figura 1. Distribuição por classes de procedências das espécies registradas na arborização de vias públicas de Farol - PR

Figure 1. Distribution by class origins of the species recorded in the greening of public roads of Farol - PR

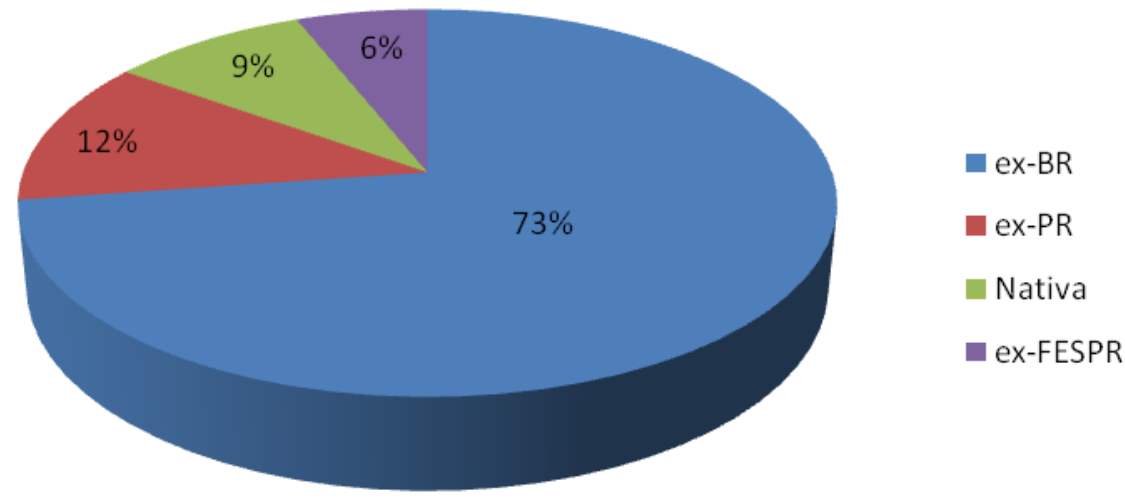

Blum et al. (2008) relatam que inventários realizados em diversas cidades brasileiras apresentam o predomínio das espécies exótica/exóticas invasoras sobre as nativas. Os mesmos autores apontam que apenas $24,1 \%$ das espécies amostradas no município de Maringá - PR são nativas. Biondi e Pedrosa-Macedo (2007) registraram em Curitiba - PR que $58 \%$ das espécies são exóticas, mas salientam que apenas 4,9\% destas são oficialmente invasoras, entretanto $42 \%$ (do total) possuem potencial invasor. Dantas e Souza (2004) também registraram maior freqüência de espécies exóticas sobre as nativas. Em três bairros de Campo Mourão - PR, Sampaio et al. (2011) registraram 73,08\% de espécies exóticas.

\section{CONCLUSÕES}

Embora constatemos que o número de espécies exóticas superara o de espécies nativas, a quantidade de indivíduos de espécies nativas é maior na composição da arborização urbana do município. Algumas destas espécies exóticas presentes oferecem riscos à biodiversidade nativa, como Leucaena leucocephala e Melia azedarach sendo necessária retirada planejada e gradativa substituição por espécies nativas, que se adéqüem da melhor maneira ao local. Por outro lado, a espécie exótica Murraya paniculata apresenta riscos à citricultura.

Ainda tem as espécies que não causam danos a biodiversidade nativa, mas sim a estrutura física dos municípios, causando transtornos com a fiação elétrica, ruas e calçadas, 
como Delonix regia, Tipuana tipu, Terminalia catappa (exótica invasora), Ficus benjamina e Ligustrum lucidum (exótica invasora), as quais também devem ser retiradas e substituídas.

Para a escolha das espécies adequadas a tipologia florestal e ao local, é necessário planejamento, para que as espécies desempenhem o papel de contribuir para o micro clima, conforto térmico, sombreamento, apresentar participação efetiva na polinização e dispersão, além de serem capazes de embelezar as ruas, praças e avenidas.

Devem-se considerar as especificações técnicas da Sociedade Internacional de Arborização (ISA) que orienta a utilização de sete a dez espécies de diferentes famílias botânicas e que cada espécie não ultrapasse 10-15\% da composição arbórea urbana. Esse aumento de freqüência de diferentes espécies nativas na arborização de vias públicas de Farol significa a viabilidade de uma arborização ecológica, valorizando espécies e ecossistemas autóctones.

\section{REFERÊNCIAS}

ALVAREZ, I. A. Qualidade do espaço verde urbano: uma proposta de índice de avaliação. 2004. 187p. Tese (Doutorado em Agronomia). Escola Superior de Agricultura Luiz de Queiroz, Universidade de São Paulo, 2004.

ANGIOSPERM PHYLOGENY GROUP (APG) III. An update of the Angiosperm Phylogeny Group classification for the orders and families of flowering plants: APG III Botanical. Journal of the Linnean Society, [s.n.], não paginado, 2009.

BECKES, P., IRGANG B. Árvores cultivadas no sul do Brasil - guia de identificação de interesse paisagístico das principais espécies exóticas. Editora Paisagem do Sul, $1^{\circ}$. Ed, v. 1, 2005.

BIONDI, D.; ALTHAUS, M. Árvores de rua de Curitiba - cultivo e manejo. Ed. FUPEF 177p. Curitiba, 2005.

BIONDI, D.; PEDROSA-MACEDO, J. H. Plantas Invasoras Encontradas na Área Urbana de Curitiba (PR). FLORESTA, Curitiba, PR, v. 38, n. 1, jan./mar. 2008.

BLUM, C. T.; BORGO, M.; SAMPAIO, A. C. F. Espécies exóticas invasoras na arborização de vias públicas de Maringá - PR. Revista da Sociedade Brasileira de Arborização Urbana, Piracicaba, v.3, n.2, jun. 2008, p.78-97.

BRASIL. Lei no 15953, de 24 de setembro de 2008. Casa Civil do Governo do Estado do Paranná. Poder Executivo, Curitiba, PR. 24 de setembro de 2008. № 7813. Disponível em: 
< http://celepar7cta.pr.gov.br/SEEG/sumulas.nsf/319b106715f69a4b03256efc00601826/fd55 a 2015 8bac3fa832574db0045375d?OpenDocument>. Acesso em 12 jun. 2012.

COPEL - COMPANHIA PARANAENSE DE ENERGIA. Arborização de vias Públicas: Guia para Municípios. 2009. Disponível em: < http://www.copel.com/hpcopel/guia_arb/index. html>. Acesso em 10 mai. 2012.

DANTAS, I. C.; SOUZA, C. M. C. Arborização urbana na cidade de Campina Grande - PB: Inventário e suas espécies. Revista de Biologia e Ciências da Terra, Campina Grande, v.4, n.2, dez. 2004.

DARRIGRAN, G. A. Invasores em La Cuenca Del Plata. Rev. Ciencia Hoy. v. 7, n. 38, 1997.

EMBRAPA, 2006. Levantamento de reconhecimento dos solos do Estado do Paraná. Londrina: EMBRAPA-SNLCS/SUDESUL/IAPAR, Tomo I, 414p.

INSTITUTO AMBIENTAL DO PARANÁ. PORTARIA, IAP n 125 de 07 de agosto de 2009. Reconhece a Lista Oficial de Espécies Exóticas Invasoras para o Estado do Paraná,estabelece normas de controle e dá outras providências. Disponível em<http://www.iap.pr.gov.br/arquivos/File/Legislacao_ambiental/Legislacao_estadual/PORT ARIAS/PORTARIA_IAP_125_2009_ESPECIES_EXOTICAS.pdf>. Acesso em: 09 mai. 2012.

IBGE - INSTITUTO BRASILEIRO DE GEOGRAFIA E ESTATÍSTICA. 2010. Disponível em: <http://www.ibge.gov.br/cidadesat/topwindow.htm>. Acesso em: 09 mai. 2012.

INSTITUTO HÓRUS DE DESENVOLVIMENTO E CONSERVAÇÃO AMBIENTAL - Base de dados nacional de espécies exóticas invasoras, I3N Brasil, Florianópolis - SC. Disponível em: <http://i3n.institutohorus.org.br>. Acesso em: 17 jul. 2012.

IOSSI, E.; SADER, R.; PIVETTA, K.F.L.A; BARBOSA, J.C. Efeitos de substratos e temperaturas na germinação de sementes de tamareira-anã (Phoenix roebelenni O'Brein). Revista Brasileira de Sementes, Brasília, v.25, n. 2, p.63-69, 2003.

KÖPPEN, W. Climatologia. Mexico: Fondo de Cultura Economica, 1978. 478p.

LISTA DE ESPÉCIES DA FLORA DO BRASIL, 2012. INSTITUTO DE PESQUISA JARDIM BOTÂNICO, RIO DE JANEIRO, 2012. Disponível em:<http://floradobrasil.jbrj.gov.br/2012>. Acesso em: 09 mai. 2012.

LORENZI, H.; SOUZA, H.M.; TORRES, M.A.V.; BACHER, L.B. Árvores Exóticas no Brasil: madeiras, ornamentais e aromáticas. Instituto Nova Odessa: Plantarum de Estudos da Flora, LTDA, São Paulo, 2003. 
LORENZI, H.; SOUZA, H. M.; COSTA, J. T. M.; CERQUEIRA, L. S. C.; FERREIRA, E. Palmeiras brasileiras: e exóticas cultivadas. Instituto Nova Odessa: Plantarum de Estudos da Flora, LTDA, São Paulo, 2004.

MARTINI, M. Projeto de lei N.2897 de 2008. Disponível em www.miguelmartini.com. Acesso em 01/07/2008.

MARTINS, E.FAROL 10 ANOS. Revista Informativa Prefeitura Municipal de Farol. Edição especial, 2003.

MATOS, E.; QUEIROZ, L.P. de. Árvores para cidades. Salvador: Ministério Publico da Bahia: Solisluna, 2009. 340p.

MELO, E. F. R. Q.; ROMANINI, A. Praça Ernesto Tochetto: importância da sua preservação histórica e aspectos de sua arborização. Revista da Sociedade Brasileira de Arborização Urbana, Piracicaba, v.3, n.1, p.54-52, 2008.

MMA - MINISTÉRIO DO MEIO AMBIENTE. 2012. Espécies Exóticas Invasoras. Disponível em: <http://homolog-w.mma.gov.br/index.php?ido=conteudo.monta\&id Estrutura=174>. Acesso em 12 mai. 2012.

OLIVEIRA, A. C. R. de; CARVALHO, S. M. Arborização De Vias Públicas E Aspectos SócioEconômicos De Três Vilas De Ponta Grossa, PR. REVSBAU, Piracicaba - SP, v.5, n.3, p.42-58, 2010.

SAMPAIO, A. C. F.; ECKER, A. E. do A.; MARANGONI, C. J.; FIORESE, L. M. R.; SORDI, E.A. Espécies exóticas invasoras na arborização de vias públicas de três bairros de Campo Mourão - PR. Campo Digit@I, v.6, n.1, p.31-43, Campo Mourão, jan/jul., 2011.

SEIFFERT, N. F.; THIAGO, L. R. L. S. Legumineira: Cultura Forrageira para Produção de Proteína. Circular Técnica, 13. Embrapa Gado de Corte. Campo Grande, MS. 1983. Disponível em: <http://www.cnpgc.embrapa.br/publicacoes/ct/ct13/index.html>. Acesso em: 14 jun. 2012.

THE INTERNATIONAL PLANT NAME INDEX. 2012. Disponível em: < http://www.ipni.org/ index.html>. Acesso em: 14 jun. 2012.

VELOSO, H. P.; GÓES-FILHO, L. Fitogeografia brasileira - classificação fisionômico ecológica da vegetação neotropical. Boletim Técnico Projeto RADAMBRASIL - Série Vegetação, Salvador, n.1, p. 1-80, 1982.

VELOSO, H.P.; RANGEL FILHO, A.L.R.; LIMA, J.C.A. Classificação da vegetação brasileira, adaptada a um sistema universal. IBGE, Departamento de Recursos Naturais e Estudos Ambientais. Rio de Janeiro, 1991. 124 p. 
ZALBA, S. M. Introdução às Invasões Biológicas - Conceitos e Definições. In: BRAND, K. América do Sul invadida. A crescente ameaça das espécies exóticas invasoras. Cape Town: Programa Global de Espécies Invasoras - GISP, p. 4-5, 2006.

ZILLER, S. R. Plantas Exóticas Invasoras: A ameaça da contaminação biológica. Ciência Hoje, v. 30, n. 17p. 77-79, 2001. 